\title{
Results of surgical treatment of patients with carpal tunnel syndrome depending on the severity of the disease
}

\author{
O.M. Semenkin ${ }^{2,1}$, S.N. Izmalkov ${ }^{1}$, A.N. Bratiichuk ${ }^{1}$, E.B. Solopikhina ${ }^{2}$, S.V. Balakleets ${ }^{2}$, \\ M.A. Bogdanova ${ }^{2}$, N.A. Kniazev ${ }^{1}$
}

${ }^{1}$ Samara State Medical University, Samara, Russian Federation

${ }^{2}$ V.D. Seredavin Samara Regional Clinical Hospital, Samara, Russian Federation

\begin{abstract}
Introduction Although surgical treatment of carpal tunnel syndrome (CTS) is known to be highly effective outcomes may not be equally satisfactory for the patients due to severity of clinical presentation and objectifying assessment of the condition. Purpose Provide clinical evaluation of outcomes of surgical treatment of CTS using questionnaires and electroneuromyography (ENMG) findings depending on baseline severity of the condition. Material and methods The review included 161 patients who underwent 189 operations of open decompression of the median nerve using mini-access. The patients were assigned to three groups with mild (Group I), moderate (Group II) and severe (Group III) CTS. Evaluations were produced at 6 weeks, 3, 6 and 12 months following the surgery. Results The majority of patients showed positive dynamics, and delayed recovery of the wrist function was noted in Group III at a 12-month follow-up. Patients of Group III exhibited spasmodic improvement of the wrist function at 6-week-to-3-month follow-up. Conclusion Open decompression of the median nerve performed for patients with CTS using mini-approach facilitated substantial clinical and functional improvement in most cases. However, the most favorable results could be provided for mild and moderate CTS.
\end{abstract}

Keywords: carpal tunnel syndrome, surgical treatment

\section{INTRODUCTION}

Carpal tunnel syndrome (CTS) is the most common ischemic compression neuropathy of the upper limb. It causes pain, numbness and tingling in the first three fingers of the hand, thenar muscle wasting and a decrease in hand function. The condition can be detected using a combination of the history, a physical examination and electroneuromyography (ENMG) test and ultrasonography (US) $[1,2]$. Conservative treatment may be offered initially to patients with mild to moderate carpal tunnel syndrome. Options include splinting, physical therapy, oral NSAIDs and local corticosteroid injections [3]. Patients with severe carpal tunnel syndrome or whose symptoms have not improved after conservative therapy should be offered surgical decompression $[4,5]$. Although surgical treatment lead to better outcome than do non-surgical treatment it can be associated with unsatisfactory outcomes due to severity of baseline morphological changes in the carpal tunnel [6-8]. ENMG is reported to have higher specificity and sensitivity than US in detecting CTS [9-10]. Severity grading of CTS allows comparison of surgical outcomes and preoperative characteristics, along with objective assessment with a limited number of papers elucidating the issue [11-15].

The purpose of the research was to provide clinical evaluation of outcomes of surgical treatment of CTS using questionnaires and electroneuromyography (ENMG) findings depending on baseline severity of the condition.

\section{MATERIAL AND METHODS}

The present study was based on a review of 230 patients suffering from idiopathic CTS who underwent a similar surgical treatment between 2014 and 2019 for pain relief. Sixty nine patients with chronic renal failure, rheumatoid arthritis, concomitant cubital tunnel syndrome, posttraumatic conditions of the hand bones and wrist joint, who refused to participate in the study and left before its completion for other reasons were excluded from the study. So, the review enrolled 151 female and 10 male patients with the total 161 participants aged 34 to 81 years with the mean follow-up of $56.3 \pm 8.4$ years performed at $11 / 2$,
3, 6 and 12 months postsurgery. Unilateral procedure was produced for 133 individuals including 88 rightsided and 45 left-sided interventions. Twenty eight patients underwent bilateral procedures on both hand with an interval of at least three months. The review finally included 161 patients who underwent 189 hand surgeries. A surgery performed for one hand was regarded as a clinical case. According to the classification offered by Beck J. D. et al. (2013) [12], all patients were divided into three clinical groups depending on measurements of the distal motor latency (DML) of the median nerve (Table 1). 
Patients distributed by clinical groups

\begin{tabular}{|c|c|c|c|c|}
\hline \multirow{2}{*}{ Clinical group } & \multirow{2}{*}{ Severity of CTS } & \multirow{2}{*}{ DML, ms } & \multicolumn{2}{|c|}{ Number of clinical cases } \\
\cline { 4 - 5 } & & $4-5.4$ & 53 & $\%$ \\
\hline Group I & Mild & $5.5-7.2$ & 61 & 28 \\
\hline Group II & Moderate & $>7.2$ & 75 & 32.3 \\
\hline Group III & Severe & - & 189 & 100.0 \\
\hline Total : & - & &
\end{tabular}

Indications to surgery included CTS diagnosed by the hand surgeon and verified by ENMG, no improvement within 3 months of nonsurgical treatment, and negative dynamics in ENMG findings. Subjects were clinically evaluated with the flick, Phalen, and Tinel maneuvers, and scratch test. The Boston Carpal Tunnel Questionnaire (BCTQ), a disease-specific measure of self-reported symptom severity and functional status, was used to evaluate outcomes. It has two distinct scales, the Symptom Severity Scale (SSS) uses a five-point rating scale and the Functional Status Scale (FSS) to be rated for degree of difficulty on a five-point scale. Each scale generates a final score which ranges from 1 to 5 , with a higher score indicating greater disability [16-17]. ENMG was performed with a Viking Quest equipment (Nicolet Biomedical) with a four-channel amplifier (VikingQuest) using SE-2 recording cutaneous silver electrodes placed $2 \mathrm{~cm}$ from each other. ENMG was used to measure four parameters including the amplitude of M-response from the abductor pollicis brevis (APB), the distal motor latency (DML) of the median nerve, motor conduction velocity (MCM) and sensory conduction velocities (SCV) of the median nerve.

Statistical analysis was performed with SPSS Version 25.0 statistic software package (IBM SPSS Statistics, USA). The Kruskall-Wallis H test was used for comparing independent samples and the MannWhitney-Wilcoxon and Bonferroni corrections were applied for comparisons between the groups. The Wilcoxon signed-rank test was used to analyze data in two related paired samples. The Kaplan-Meier

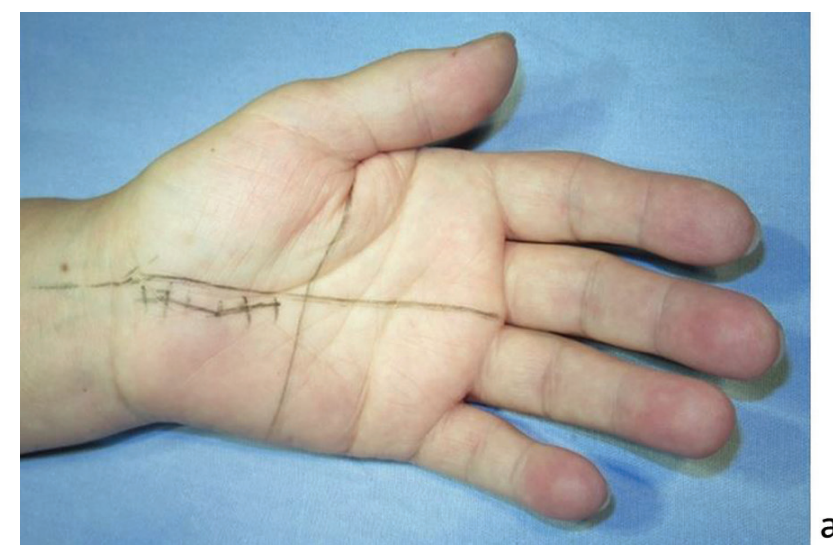

estimator was used to evaluate restoration of the SCV of the median nerve. Data were expressed as means (M) \pm standard deviation (SD) with medians and quartiles calculated and box plots constructed. In addition, the Spearman Rank correlation was used to measure the strength of a relationship between paired data. For calculations, a significance level of $<0.05$ was adopted.

Surgical technique. Open decompression of the median nerve was performed with the patient in supine position and the upper limb being abducted and supinated. A pneumatic cuff tourniquet was applied to the shoulder for exsanguination. A combination of intravenous sedation and local anesthesia was used for anesthesia. A slightly arched or Z-shaped incision $25 \mathrm{~mm}$ long ("mini-open incision") was made parallel to the crease of the thenar eminence, outside the projection of the hook of the hamatum and the distal crease of the wrist in all the cases (Fig. 1a). The palmar branch of the median nerve was thoroughly taken care of. An arcwise longitudinal incision was used to dissect the palmar aponeurosis. The flexor retinaculum was dissected over the volar and ulnar surface to avoid injury to the motor branch of the median nerve (Fig. 1b).

The forearm fascia was dissected in the distalto-proximal direction to reach the level of the distal crease of the wrist. The palmar aponeurosis and the skin were sutured layer after layer. The wrist was fixed with a removable splint for 3 weeks. Patients could move the fingers and the wrist starting from the second postoperative day avoiding flexion of the hand. Wrist orthosis was recommended to use for heavy physical activity.

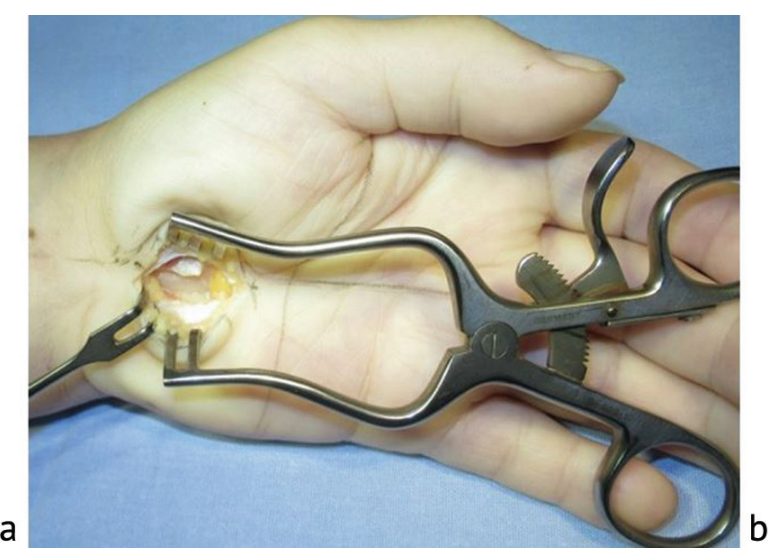

Fig. 1 Intraoperative position of the hand showing (a) operative approach tracking; $(\boldsymbol{b})$ appearance of surgical wound with the flexor retinaculum dissected 


\section{RESULTS}

The results of treatment are summarized in Table 2 including six parameters (BCTQ SSS, BCTQ FSS, APB, DML, MCV, SCV) in three clinical groups over a follow-up period of 12 months.

Patients of Groups I and II showed significant clinical improvement with the parameters being well within acceptable limits of normal. There were significant differences in BCTQ SSS, BCTQ FSS, DML and SCV at the baseline and at a 12-month follow-up $(\mathrm{p}<0.001)$. Although patients of Groups III showed statistically significant improvement in the six parameters at oneyear follow-up the mean measurements were not within acceptable limits of normal.

In addition to changes in parameters seen at 12 months there were dynamics in the measurements observed at earlier follow-up period between the groups. Patients of the three groups demonstrated a significant improvement of BCTQ SSS scores at all time points compared with the baseline measurements (Fig. 2). Greater changes in BCTQ SSS scores were observed at 11/2 months. BCTQ SSS scores appeared to improve by $47 \%, 42 \%$ and $31 \%$ in Groups I, II, III at $11 / 2$ months, respectively. Significant differences in BCTQ SSS scores were registered between Group I and Group III, between Group II and Group III. No significant differences were seen at 3, 6 and 12 months between the groups.
Similar improvement in BCTQ FSS scores was seen among the groups. BCTQ FSS scores significantly improved at $11 / 2$ months. BCTQ FSS scores were shown to improve by $34 \%, 28 \%$ and $17 \%$ in Groups I, II, III at $11 / 2$ months, respectively (Fig. 3). Significant differences in BCTQ FSS scores were seen between Group I and Group III. No significant differences were seen at 3, 6 and 12 months between the groups.

Along with the questionnaire data, the ENMG findings indicated to gradual improvement in hand and wrist function. Although gradual increase in M-response from APB was seen in all groups it occurred in a slow manner showing no significant differences with baseline measurements (Fig. 4). No changes in M-response from APB was observed at $11 / 2$ months in the three groups as compared to the baseline. Significant changes in M-response from APB was observed at 3 months in group III with the measurements approximating to those in Groups I and II with a later lagging-behind tendency. Measurements of M-response from APB were well within acceptable limits of normal in Groups I and II at 12 months being $6.37 \pm 2.32 \mathrm{mV}$ and $6.30 \pm 2.00 \mathrm{mV}$, respectively. Group III demonstrated increase in M-response by $4.11 \pm 2.30 \mathrm{mV}(\mathrm{p}<0.001)$ with normal value being $>6 \mathrm{mV}$.

Table 2

Outcomes of surgical treatment of CTS patients

\begin{tabular}{|l|c|c|c|c|c|c|c|c|c|c|}
\hline \multirow{2}{*}{ Parameters } & \multirow{2}{*}{ Normal } & \multicolumn{9}{|c|}{ Clinical groups } \\
\cline { 3 - 12 } & & \multicolumn{3}{|c|}{ Group I, $\mathrm{n}=53$} & \multicolumn{3}{c|}{ Group II, $\mathrm{n}=61$} & \multicolumn{3}{c|}{ Group III, $\mathrm{n}=75$} \\
\cline { 3 - 12 } & Preoperative & $\begin{array}{c}\text { At } \\
12 \mathrm{months}\end{array}$ & $\mathrm{p}$ & Preoperative & $\begin{array}{c}\text { At } \\
12 \mathrm{months}\end{array}$ & $\mathrm{p}$ & Preoperative & $\begin{array}{c}\text { At } \\
12 \mathrm{months}\end{array}$ & $\mathrm{p}$ \\
\hline $\begin{array}{l}\text { BCTQ SSS, } \\
\text { scores }\end{array}$ & 1.0 & $3.63 \pm 0.68$ & $1.62 \pm 0.73$ & $<0.001$ & $3.65 \pm 0.74$ & $1.69 \pm 0.56$ & $<0.001$ & $3.87 \pm 0.71$ & $1.71 \pm 0.65$ & $<0.001$ \\
\hline $\begin{array}{l}\text { BCTQ FSS, } \\
\text { scores }\end{array}$ & 1.0 & $3.20 \pm 0.86$ & $1.51 \pm 0.42$ & $<0.001$ & $3.25 \pm 0.91$ & $1.72 \pm 0.62$ & $<0.001$ & $3.52 \pm 0.87$ & $1.85 \pm 0.82$ & $<0.001$ \\
\hline $\mathrm{APB}, \mathrm{mV}$ & $>6.0$ & $5.93 \pm 2.66$ & $6.37 \pm 2.32$ & $=0.455$ & $4.84 \pm 2.44$ & $6.30 \pm 2.00$ & $=0.008$ & $2.37 \pm 2.25$ & $4.11 \pm 2.30$ & $<0.001$ \\
\hline $\mathrm{DML}, \mathrm{ms}$ & $<4.2$ & $4.65 \pm 0.44$ & $3.80 \pm 0.29$ & $<0.001$ & $6.29 \pm 0.54$ & $4.22 \pm 0.44$ & $<0.001$ & $9.03 \pm 1.72$ & $5.26 \pm 1.13$ & $<0.001$ \\
\hline $\mathrm{MCV}, \mathrm{m} / \mathrm{s}$ & $>50$ & $53.36 \pm 5.10$ & $55.19 \pm 3.86$ & $=0.064$ & $50.70 \pm 5.34$ & $53.91 \pm 3.62$ & $=0.006$ & $45.58 \pm 8.70$ & $46.81 \pm 9.56$ & $<0.001$ \\
\hline $\mathrm{SCV}, \mathrm{m} / \mathrm{s}$ & $57-71$ & $33.57 \pm 13.13$ & $49.09 \pm 8.74$ & $<0.001$ & $30.01 \pm 6.36$ & $44.51 \pm 4.95$ & $<0.001$ & $23.62 \pm 6.76$ & $30.98 \pm 10.96$ & $<0.001$ \\
\hline
\end{tabular}

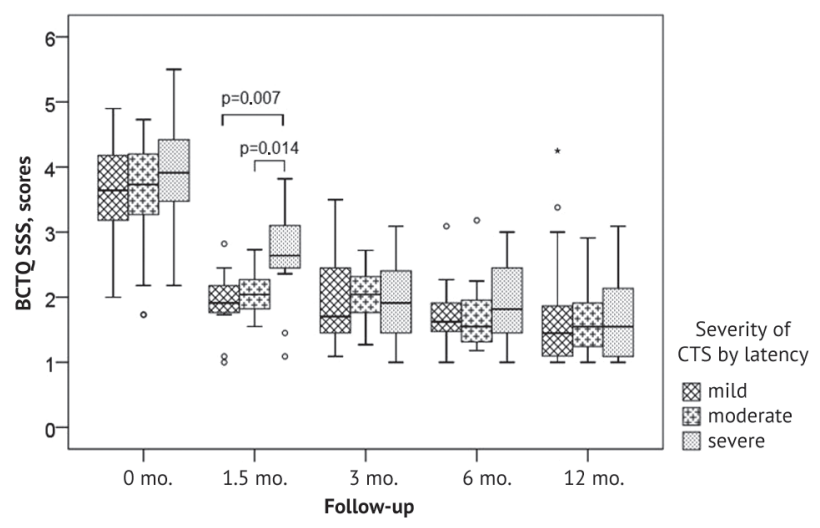

Fig. 2 Dynamics in BCTQ SSS scores

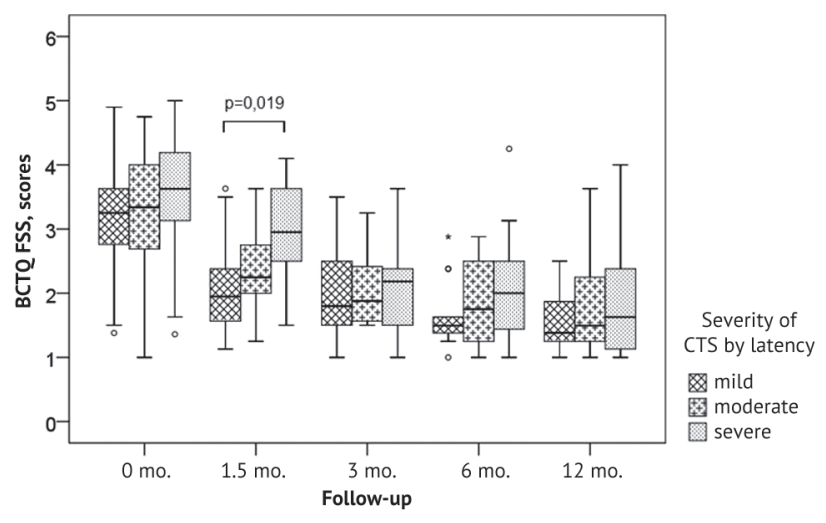

Fig.3 Dynamics in BCTQ FSS scores 


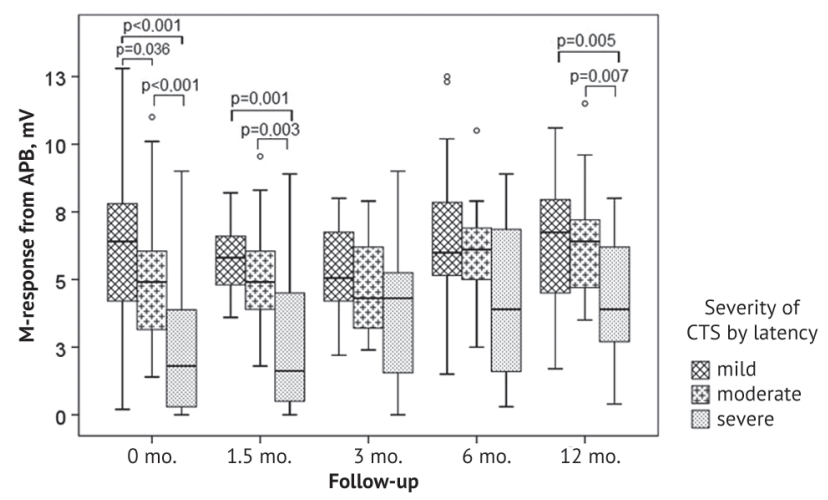

Fig. 4 Dynamics in the amplitude of M-response from abductor pollicis brevis, $\mathrm{mV}$

Distal motor latency of the median nerve showed positive dynamics at all time points in all groups with greater changes observed at 12 months (Fig. 5). The mean distal motor latency decreased from $4.65 \pm 0.44 \mathrm{~ms}$ to $3.80 \pm 0.29 \mathrm{~ms}(\mathrm{p}<0.001)$ in Group I, from $6.29 \pm 0.54 \mathrm{~ms}$ to $4.22 \pm 0.44 \mathrm{~ms}$ $(\mathrm{p}<0.001)$ in Group II and from $9.03 \pm 1.72 \mathrm{~ms}$ to $5.26 \pm 1.13 \mathrm{~ms}(\mathrm{p}<0.001)$ in Group III, with normal of $<4.2 \mathrm{~ms}$. Significant differences in DML were registered between Group I and Group III, between Group II and Group III.

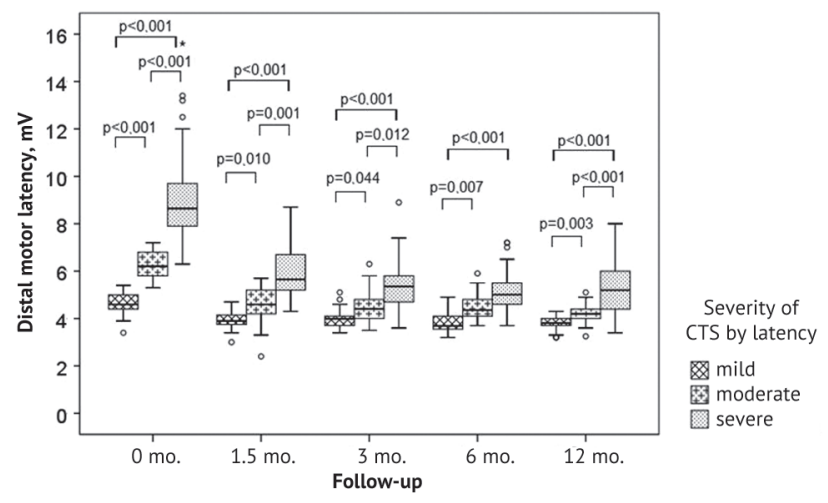

Fig. 5 Dynamics in distal motor latency of the median nerve, ms

Although gradual increase in motor conduction velocity of the median nerve was seen in all groups (Fig. 6) it occurred in a slow manner in Group III showing no significant differences with baseline measurements. Measurements of motor conduction velocity were well within acceptable limits of normal in Groups I and II at 12 months being $55.19 \pm 3.86 \mathrm{~m} / \mathrm{s}$ and $53.91 \pm 3.62 \mathrm{~m} / \mathrm{s}$, respectively. Group III demonstrated low measurements of $46.81 \pm 9.56 \mathrm{~m} / \mathrm{s}$, with the normal value being $>50 \mathrm{~m} / \mathrm{s}$. Significant differences in MCV were registered between Group I and Group III, between Group II and Group III at all time points.

Sensory conduction velocity of the median nerve gradually improved at all time points in all groups (Fig. 7). Significant changes in SCV were observed in Group I and Group II measuring $49.09 \pm 8.74$ and $44.51 \pm 4.95 \mathrm{~m} / \mathrm{s}$, respectively. SCV decreased to $3098 \pm 10.96 \mathrm{~m} / \mathrm{s}$ in Group III, with normal range of $57-71 \mathrm{~m} / \mathrm{s}$. Significant differences in SCV were registered between Group I and Group III, between Group II and Group III at all time points. It should be noted that SCV could not be identified in $63(37.3 \%)$ patients preoperatively and measured zero. Among those, $54(85.7 \%)$ patients were assigned to Group III with the maximum CTS severity.

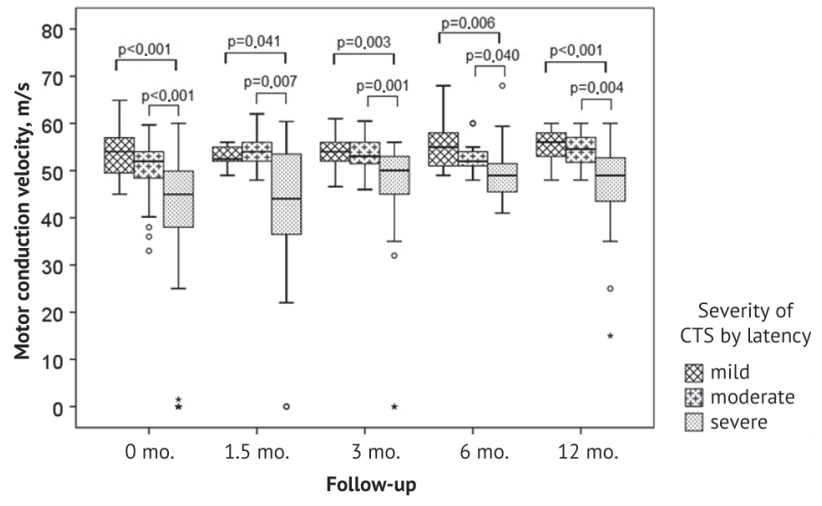

Fig. 6 Dynamics in motor conduction velosity of the median nerve, $\mathrm{m} / \mathrm{s}$

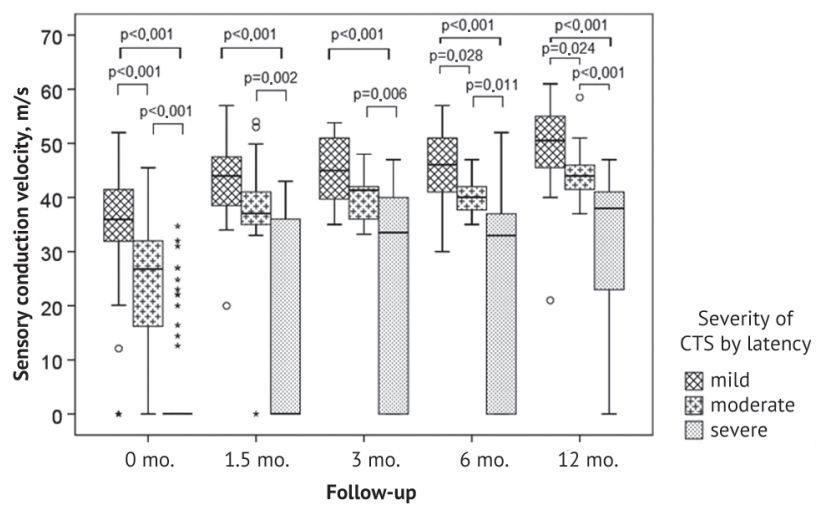

Fig. 7 Dynamics in sensory conduction velosity of the median nerve, $\mathrm{m} / \mathrm{s}$

The Kaplan-Meier estimator, a non-parametric statistic that takes into account some types of censored data used to estimate the survival function from lifetime data, was employed to identify time points of SCV recovery [18]. The plot of the Kaplan-Meier estimator showed (Fig. 8) faster recovery in patients with the baseline zero SCV in Groups I and II altogether as compared to Group III starting from 6 weeks.

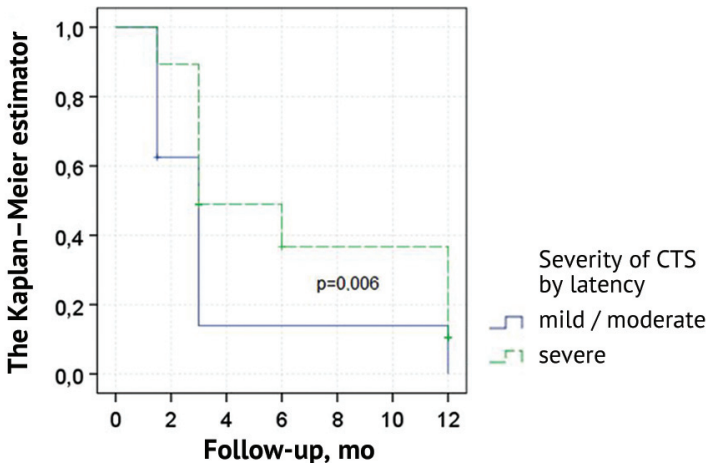

Fig. 8 A plot of the Kaplan-Meier estimator showing recovery of sensory conduction velocity depending on CTS severity 
The differences in SCV were most significant at a 3-month follow-up with the Kaplan-Meier estimator measuring $0.14 \pm 0.09$ conv. units in Groups I and II altogether and only $0.49 \pm 0.07$ conv. units in Group III. Patients with the baseline zero SCV achieved recovery in $94 \%$ in Groups I and II altogether and in $83 \%$ in Group III ( $\mathrm{p}=0.006$ according to the log-rank test).

With general tendency to positive dynamics in the parameters measured, patients of Group III showed a slower recovery of the upper limb function as compared with patients of Groups I and II. Although patients of Group III failed to have the measurements within acceptable limits of normal at a 12-month follow-up they could benefit from the surgery in any way showing greater changes in functional recovery at $11 / 2$ to 3 months.

There is a clinical instance of a 52-year-old patient K., a tailoress, presented with numbness and pain in the first three fingers of the left hand that were worse in the morning. She was treated conservatively for a year and showed slight improvement. The pain gradually increased in intensity being often worse at night. She suffered from swollen hands in the morning with fingers movements being difficult. Her occupational skills and activities of daily living decreased significantly.

Physical exmination revealed no changes in the appearance of the left hand and it looked much like the right hand. She presented with full range of motion in the digital joints. The lady experienced pain over the carpal canal that irradiated in the first three fingers. Phalen and Tinel tests were positive. Pain intensity at night scored 7.5 on the visual analog scale (VAS). She found herself waking up five times a night or more with a pain. BCTQ SSS and BCTQ FSS scored 4.46 and 3.13, respectively. She experienced marked hand weakness. Her activities of daily living were much reduced due to pain and impaired finger sensitivity. EMG revealed signs of CTS with M-responses from APB measuring $2.8 \mathrm{mV}$; MCV, $48 \mathrm{~m} / \mathrm{s}$; DML, $5.0 \mathrm{~ms} ; \mathrm{SCV}, 36 \mathrm{~m} / \mathrm{s}$.

InAugust 2019, the patient underwent decompression of the median nerve on the left side using a miniincision and had pain relief immediately after surgery. The postoperative period was uneventful. The wound healed with primary intension. The patient followed the postoperative recommendations very carefully. The patient presented no complaints at 6-month followup and could return to her job with neither numbness nor tingling in the fingers. She had no pain at rest, but pain intensity scored 1.8 after exercises. She had full range of motion in the digital joints (Fig. 9). The patient experienced mild hand weakness at physical activity. She showed positive dynamics in the measurements with BCTQ SSS scored 1.36 and BCTQ FSS scored 2.0. EMG findings included $\mathrm{APB}$ of $6.1 \mathrm{mV}$; MCV of $53 \mathrm{~m} / \mathrm{s}$; DML, $3.6 \mathrm{~ms}$; SCV, $54 \mathrm{~m} / \mathrm{s}$ (Fig. 10). The patient was quite satisfied with the outcome.
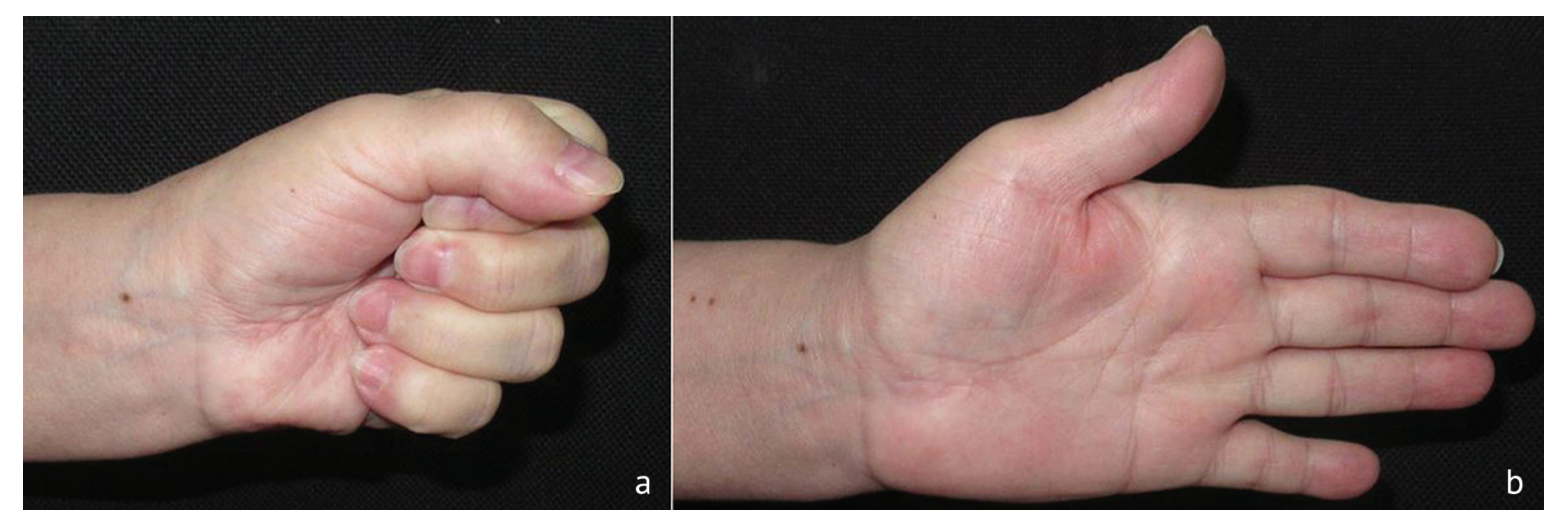

Fig. 9 Photograph of the hand of patient K. showing active finger motion at 6-month follow-up during (a) flexion and (b) extension
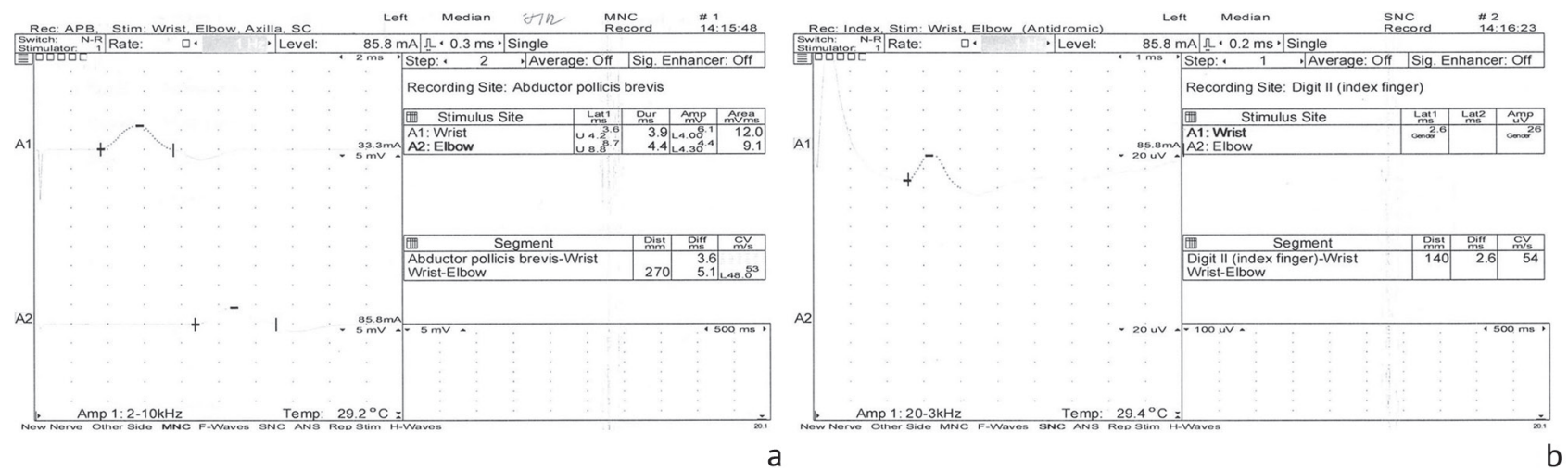

Fig. 10 ENMG findings of patient K. at 6-month follow-up showing (a) M-response from APB of the left hand; (b) SCV of the median nerve 


\section{DISCUSSION}

Operative decompression of the median nerve in the carpal canal can be performed using mini-access, standard approach or an endoscope. J. Iida et al. (2008) reported completely relieved nocturnal or daytime dysesthesia in $94 \%$ of patients and substantial pain relief in $4 \%$ due to minimum incision open carpal tunnel release. H. Aslani et al. (2012) [19] reported the best improvement in night pain relief, followed by parasthesia at a 4-month follow-up in 105 patients of the endoscopic and mid-palmar mini incision group as compared to regular open incision. D. Louie et al. (2013) [20] reported $88 \%$ of 113 patients being either completely satisfied or very satisfied with the surgery at an average of 13 years after open carpal tunnel release. M. Larsen et al. (2013) [21] compared the results of carpal tunnel release using classic incision, short incision, or endoscopic technique in total 90 consecutive cases and found no significant differences in pain, paraesthesiae, range of motion at 6 months of follow-up.

In our series, minimum incision open carpal tunnel release allowed us to dissect the flexor retunaculum and decompress the median nerve in a minimally invasive manner. We could avoid injury to the palmar sensory branch and the thenar motor branch of the median nerve, infection and complex regional pain syndrome in all 189 cases. Four $(2.1 \%)$ patients experienced hypersensitivity of the postoperative scar and seven $(3.7 \%)$ had moderate thenar and hypothenar pain at 3-month follow-up with the symptoms treated conservatively.

Outcomes in our series are partially in line with the reported data irrespective of the CTS severity. J. Iida et al. (2008) examined the surgical outcomes of the affected hands based on preoperative electrophysiological severity. They reported complete relief in $100 \%$ of the hands in the early group, $99 \%$ in the mild group, $94 \%$ in the moderate group and $50 \%$ in the severe group. The latter could not demonstrate normal ENMG findings even at a 12-month followup. The authors recommended early surgical treatment prior to clinical manifestations of CTS rated as severe. M. Mondelli et al. (2000) [22] reported significant improvement in the mean BCTQ scores and distal sensory and motor conduction velocities in the median nerve at a 1-month follow-up with further significant improvement found at 6 months. The authors reported no correlation between the mean BCTQ scores and ENMG findings. This correlation was detected in our series at 11/2-month follow-up when comparing BCTQ scores and the M-response amplitude $(\mathrm{p}=0.003)$, $\operatorname{DML}(\mathrm{p}=0.006)$ and $\operatorname{SCV}(\mathrm{p}=0.002)$. There was also a significant correlation found between BCTQ FSS score and a decrease in DML values $(p=0.030)$ at a 12-month follow-up.

J. Iida et al. (2008) reported nocturnal or daytime dysesthesia being completely relieved in $94 \%$ of the hands treated with minimum incision open carpal tunnel release.The authors reported satisfactory postoperative results regardless of the degree of preoperative electrophysiological severity if preoperative sensory nerve action potentials were detected. Patients with zero SCV cannot rely on successful surgical outcome. In out series, patients who failed to have SCV identified were assigned to severe group (Group III).

S. Kronlage and M. Menendez (2015) [23] found that patients with moderate CTS reported, on average, no symptoms, and and patients with severe disease had reduced but unresolved symptoms at 12-month follow-up. At 1 year or longer after surgery, $2 \%$ patient with moderate CTS and $19 \%$ patients with severe CTS reported continued symptoms. Patients with severe CTS experience considerable reduction in symptoms after surgery but recovery may be more prolonged and, in some cases, incomplete 12 months after carpal tunnel release, particularly with regard to numbness. Patients of Group III exhibited slow recovery of sensory conduction velocity with the parameter being not well within acceptable limits of normal at a 12-month follow-up.

K. Pedersen et al. (2017) [24] reported decrease in DML at a 11/2-month follow-up after operations using standard approach regardless of the degree of preoperative electrophysiological severity. Patients with DML of $>4.2 \mathrm{~ms}$ at baseline had DML declining linewise after surgery. With preoperative DML of $\leq 4.2 \mathrm{~ms}$ the parameter stayed stable after surgery. In our series, DML in patients of Group III underwent less changes as compared to Groups I and II. S. Cha et al. (2016) analyzed the differences in the preoperative status and final outcomes between patients with or without the motivation for prompt surgery and found that the overall outcomes of most patients, who refused/delayed surgery as the initial treatment for CTS and received conservative treatment for 6 months were inferior compared with those who agreed to operative treatment as the initial option. We did not evaluate the differences at a baseline and follow-up period. 
J. Fowler et al. (2016) [25] reported early clinical manifestations of CTS detected with ENMG and discrimination test as a time predictor to resolution of symptoms after carpal tunnel release. Improvement of severe symptoms was likely to be less meaningful and longer as compared with that noted in mild and moderate condition $(p=0.008)$. However, there were no significant differences in the resolution of symptoms between the groups of patients with mild and moderate CTS $(p=0.4)$. We observed a significant difference in the relief of CTS symptoms at $11 / 2$ and 3 months after the operation between Group I and Group III, and between Group II and Group III. All patients showed an improvement in the clinical presentation at a 12-month follow-up with almost no significant differences between the groups.

\section{CONCLUSION}

1. Open decompression of the median nerve performed for patients with CTS using miniapproach facilitated substantial clinical and functional improvement in all cases at a 12-month follow-up.

2. Patients with mild and moderate CTS showed earlier clinical and functional improvement as compared to those with severe symptoms, at least at a 11/2-month follow-up.
3. Distal motor latency, an important ENMG criterion of CTS severity, was well within acceptable limits of normal at a 12-month follow-up in most patients with mild and moderate condition. Patients with severe CTS failed to show the normal mean DML at that time point.

4. DML measurements and clinical tests were shown to be essential for effective surgical strategies in patients with mild and moderate CTS, in particular.

Declaration of Conflicting Interests: The authors declared no potential conflicts of interest with respect to the authorship and/or publication of this article.

Funding: The research was supported by the authors' personal funds.

\section{REFERENCES}

1. NovikovA.V., Shchedrina M.A., Motiakina O.P. Sovremennye predstavleniia ob etiologii i mekhanizmakh patogeneza kompressionnoishemicheskikh nevropatii verkhnei konechnosti (obzor literatury) [Modern ideas about the etiology and pathogenesis mechanisms of compression-ischemic neuropathies of the upper limb (review of the literature)]. Voprosy Travmatologii i Ortopedii, 2012, no. 3, pp. 35-39. (in Russian)

2. Bogov A.A. Jr., Masgutov R.F., Khannanova I.G., Galiamov A.R., Mullin R.I., Topyrkin V.G., Akhtyamov I.F., Bogov A.A. Sindrom zapiastnogo (karpalnogo) kanala [Carpal tunnel syndrome]. Prakticheskaia Meditsina, 2014, no. 4-2: Innovatsionnye Tekhnologii v Meditsine [Innovation Technologies in Medicine], pp. 35-40. (in Russian)

3. Hageman M.G., Kinaci A., Ju K., Guitton T.G., Mudgal C.S., Ring D. Science of Variation Group. Carpal tunnel syndrome: Assessment of surgeon and patient preferences and priorities for decision-making. J. Hand Surg. Am., 2014, vol. 39, no. 9, pp. 17991804.e1. DOI: 10.1016/j.jhsa.2014.05.035

4. Cha S.M., Shin H.D., Ahn J.S., Beom J.W., Kim D.Y. Differences in the postoperative outcomes according to the primary treatment options chosen by patients with carpal tunnel syndrome: conservative versus operative treatment. Ann. Plast. Surg., 2016, vol. 77 , no. 1 , pp. 80-84. DOI: $10.1097 /$ SAP.0000000000000598

5. Wright A.R., Atkinson R.E. Carpal Tunnel Syndrome: An Update for the Primary Care Physician. Hawaii J. Health Soc. Welf., 2019, vol. 78, no. 11 Suppl. 2, pp. 6-10.

6. Bland J.D. Treatment of carpal tunnel syndrome. Muscle Nerve, 2007, vol. 36, no. 2, pp. 167-171. [PMID: 17534984]. DOI: 10.1002/ mus. 20802

7. Verdugo R.J., Salinas R.A., Castillo J.L., Cea J.G. Surgical versus non-surgical treatment for carpal tunnel syndrome. Cochrane Database Syst. Rev., 2008, vol. 2008, no. 4, pp. CD001552. DOI: 10.1002/14651858.CD001552.pub2

8. Jarvik J.G., Comstock B.A., Kliot M., Turner J.A., Chan L., Heagerty P.J., Hollingworth W., Kerrigan C.L., Deyo R.A. Surgery versus non-surgical therapy for carpal tunnel syndrome: a randomized parallel-group trial. Lancet, 2009, vol. 374, no. 9695, pp. $1074-1081$. DOI: 10.1016/S0140-6736(09)61517-8

9. Kwon B.C., Jung K.I., Baek G.H. Comparison of sonography and electrodiagnostic testing in the diagnosis of carpal tunnel syndrome. J. Hand Surg. Am., 2008, vol. 33, no. 1, pp.65-71. DOI: 10.1016/j.jhsa.2007.10.014

10.Kaymak B., Ozçakar L., Cetin A., Candan Cetin M., Akinci A., Hasçelik Z. A comparison of the benefits of sonography and electrophysiologic measurements as predictors of symptom severity and functional status in patients with carpal tunnel syndrome. Arch. Phys. Med. Rehabil., 2008, vol. 89, no. 4, pp. 743-748. DOI: 10.1016/j.apmr.2007.09.041

11.Iida J., Hirabayashi H., Nakase H., Sakaki T. Carpal tunnel syndrome: electrophysiological grading and surgical results by minimum incision open carpal tunnel release. Neurol. Med. Chir. (Tokyo), 2008, vol. 48, no. 12, pp. 554-559. DOI: 10.2176/nmc.48.554

12.Beck J.D., Wingert N.C., Rutter M.R., Irgit K.S., Tang X., Klena J.C. Clinical outcomes of endoscopic carpal tunnel release in patients 65 and over. J. Hand Surg. Am., 2013, vol. 38, no. 8, pp. 1524-1529. DOI: 10.1016/j.jhsa.2013.05.016

13.Żyluk A., Walaszek I., Szlosser Z. No correlation between sonographic and electrophysiological parameters in carpal tunnel syndrome. J. Hand Surg. Eur. Vol., 2014, vol. 39, no. 2, pp. 161-166. DOI: 10.1177/1753193413489046

14.Kanatani T., Nagura I., Harada Y., Sumi M. The role of electrophysiological severity scales for decision-making with regard to surgery in idiopathic carpal tunnel syndrome. Kobe J. Med. Sci., 2017, vol. 63, no. 3, pp. E68-E72.

15.Ginniatulina R.I. Mezhdunarodnye podkhody k upravleniiu kachestvom meditsinskoi pomoshchi (obzor literatury) [International approaches to the management of medical care quality (review of the literature]. Nauka i Innovatsii v Meditsine, 2019, vol. 4, no. 4, pp. 38-43. (in Russian) 
16.Iusupova D.G., Suponeva N.A., Zimin A.A., Zaitsev A.B., Belova N.V., Chechetkin A.O., Gushcha A.O., Gatina G.A., Polekhina N.V., Bundkhun P., Ashrafov V.M. Validatsiia Bostonskogo Oprosnika po otsenke karpalnogo tunnelnogo sindroma (Boston Carpal Tunnel Questionnaire) v Rossii [Validation of Boston questionnaire by the assessment of carpal tunnel syndrome (Boston Carpal Tunnel Questionnaire) in Russia]. Nervno-myshechnye Bolezni, 2018, vol. 8, no. 1, pp. 38-45. (in Russian)

17.Levine D.W., Simmons B.P., Koris M.J., Daltroy L.H., Hohl G.G., Fossel A.H., Katz J.N. A self-administered questionnaire for the assessment of severity of symptoms and functional status in carpal tunnel syndrome. J. Bone Joint Surg., 1993, vol. 75, no. 11, pp. 1585-1592. DOI: 10.2106/00004623-199311000-00002

18.Izmalkov S.N., Bratiychuk A.N., Usov A.K., Galeev F.Sh., Litvinov S.A. Prognozirovanie veroiatnosti revizionnogo endoprotezirovaniia tazobedrennogo sustava s zamenoi vertluzhnogo komponenta $\mathrm{v}$ zavisimosti ot vida ego tsementnoi fiksatsii [Prediction of the probability of revision hip arthroplasty with replacement of the acetabular component depending on the type of its cement fixation]. Genij Ortopedii, 2019, vol. 25, no. 4, pp. 474-480. (in Russian)

19.Aslani H.R., Alizadeh K., Eajazi A., Karimi A., Karimi M.H., Zaferani Z., Hosseini Khameneh S.M. Comparison of carpal tunnel release with three different techniques. Clin. Neurol. Neurosurg., 2012, vol. 114, no. 7, pp. 965-968. DOI: 10.1016/j. clineuro.2012.02.017

20.Louie D.L., Earp B.E., Collins J.E., Losina E., Katz J.N., Black E.M., Simmons B.P., Blazar P.E. Outcomes of open carpal tunnel release at a minimum of ten years. J. Bone Joint Surg. Am., 2013, vol. 95, no. 12, pp. 1067-1073. DOI: 10.2106/JBJS.L.00903

21.Larsen M.B., Sørensen A.I., Crone K.L., Weis T., Boeckstyns M.E. Carpal tunnel release: a randomized comparison of three surgical methods. J. Hand Surg. Eur. Vol., 2013, vol. 38 (E), no. 6, pp. 646-650. DOI: 10.1177/1753193412475247

22.Mondelli M., Reale F., Sicurelli F., Padua L. Relationship between the self-administered Boston Questionnaire and electrophysiological findings in follow-up of surgically treated carpal tunnel syndrome. J. Hand Surg. Br., 2000, vol. 25, no. 2, pp. 128-134. DOI: 10.1054/ jhsb.2000.0361

23.Kronlage S.C., Menendez M.E. The benefit of carpal tunnel release in patients with electrophysiologically moderate and severe disease. J. Hand Surg. Am., 2015, vol. 40, no. 3, pp. 438-444.e1. DOI: 10.1016/j.jhsa.2014.12.012

24.Pedersen K., Duez V., Stallenberg B., Mavroudakis N. Evolution of clinical, electrophysiological, and radiological aspects of the carpal tunnel syndrome before and after surgery. Acta Neurol. Belg., 2017, vol. 117, no. 4, pp. 903-908. DOI: 10.1007/s13760-0170837-0

25.Fowler J.R., Munsch M., Huang Y., Hagberg W.C., Imbriglia J.E. Pre-operative electrodiagnostic testing predicts time to resolution of symptoms after carpal tunnel release. J. Hand Surg. Eur. Vol., 2016, vol. 41, no. 2, pp. 137-142. DOI: 10.1177/1753193415576248

Received: 12.05 .2020

\section{Information about the authors:}

1.Oleg M. Semenkin, M.D., Ph.D.,

Samara State Medical University, Samara, Russian Federation,

V.D. Seredavin Samara Regional Clinical Hospital, Samara, Russian Federation,

Email: olegsemenkin63@yandex.ru

2. Sergey N. Izmalkov, M.D., Ph.D.,

Samara State Medical University, Samara, Russian Federation,

Email: izmalkov@mail.ru

3. Alexander N. Bratiichuk, M.D., Ph.D.,

Samara State Medical University, Samara, Russian Federation,

Email: brat59@bk.ru

4. Elya B. Solopikhina, M.D.,

V.D. Seredavin Samara Regional Clinical Hospital, Samara, Russian Federation,

Email: ivlev63@yandex.ru

5. Svetlana V. Balakleets, M.D.,

V.D. Seredavin Samara Regional Clinical Hospital, Samara, Russian Federation,

Email: balakleyets@mail.ru

6. Maria A. Bogdanova, M.D.,

V.D. Seredavin Samara Regional Clinical Hospital, Samara, Russian Federation,

Email: mariya-a-g@yandex.ru

7. Nikita A. Kniazev, M.D.,

Samara State Medical University, Samara, Russian Federation,

Email: n.knyazev.bass@gmail.com 